\title{
Endovascular interventions in trauma, an introduction
}

\section{Introduction}

In the United States, trauma is the $3^{\text {rd }}$ leading cause of death and is the leading cause of death in patients under 45 (1). It can be broadly divided into two categories. Blunt trauma, also known as non-penetrating trauma is most often secondary to motor vehicle collisions, falls, and sports related injuries. Penetrating trauma involves piercing injury of the skin. It is broken down into two categories, projectile (e.g., gunshot wounds) and non-projectiles (e.g., stabbings). Initial triage of patients and approach to operative and endovascular interventions depend on whether injuries are blunt or penetrating (2). For example, in abdominal trauma, most patients with significant penetrating injury require urgent laparotomy whereas hemodynamically stable patients without peritoneal signs can potentially be managed non-operatively.

\section{Growing role of endovascular procedures}

The first published report of endovascular treatment in trauma was a case of hematuria and arterio-venous fistula caused by a renal biopsy which was treated with autologous blood clot embolization (3). Since this 1973 report, endovascular tools, equipment and techniques have markedly advanced (Figure 1). Likewise, endovascular interventions have come to play a pivotal role in treatment of trauma patients. The goal of endovascular embolization or other interventions is to stop bleeding without subjecting patients to the physiologic stress of surgery while often preserving normal organ tissue and function. There has been a global shift towards non-operative and often endovascular management of splenic, liver and renal trauma (4-6) and successful endovascular embolization is a key component in non-operative management. Studies have shown clear benefit of endovascular interventions in thoracic aortic (7), pelvic (8), splenic (9) and renal (10) trauma. Embolization can also be used on a case by case basis outside of these well studied locations (Figure 2).

The shift from open to endovascular interventions in trauma patients is exemplified by the use of stent graft in traumatic injury to the thoracic aorta. Traumatic thoracic aortic injury is thought to be the second leading cause of death in trauma with about $85 \%$ of patients dying before arrival $(11,12)$. Open repair of blunt thoracic aortic injury was a highly morbid procedure with a peri-operative mortality of $32 \%$ and paraplegia rates of almost $10 \%$ (13). But, with endovascular repair there is a >95\% survival and $0 \%$ paraplegia rate (14).

\section{Overview of peri-procedural care of trauma patient}

\section{Initial work-up}

Interventional radiologists and other endovascular specialists treating trauma patients need to understand the treatment framework, underlying pathophysiology, surgical alternatives to endovascular procedures in order to be useful members of the trauma team. Familiarity with Advanced Trauma Life Support (ATLS), which is both an educational program and a standardized framework for work-up of trauma patients is important. The first step in evaluation of a trauma patient is the primary survey, during which time concurrent efforts are made to identify and treat life threatening injuries using the ABCD (Airway, Breathing, Circulation, Disability) mnemonic. During airway assessment, for example, if a neck hematoma is compressing the airway, immediate endotracheal intubation is performed. Breathing assessment focuses on major disruptions in gas exchange. For example, if a significant pneumothorax is diagnosed, a chest tube is immediately placed. In evaluation of circulation, the trauma team identifies and treats causes of shock. Control of ongoing hemorrhage is the next most pressing concern; if left untreated it will progress to shock and subsequent death (15). Hemorrhagic shock does not just manifest with hypotension but rather a derangements of multiple clinical parameters including pulse rate, decreased pulse pressure (systolic blood pressure-diastolic blood pressure), increased respiratory rate, alterations in mental status and decreased urine output (16). Changes in these clinical parameters often precede hypotension and should all be considered with assessing for the presence and grade of hemorrhagic shock. With the loss of less than $15 \%$ of circulating blood volume (<750 cc, assuming circulating 

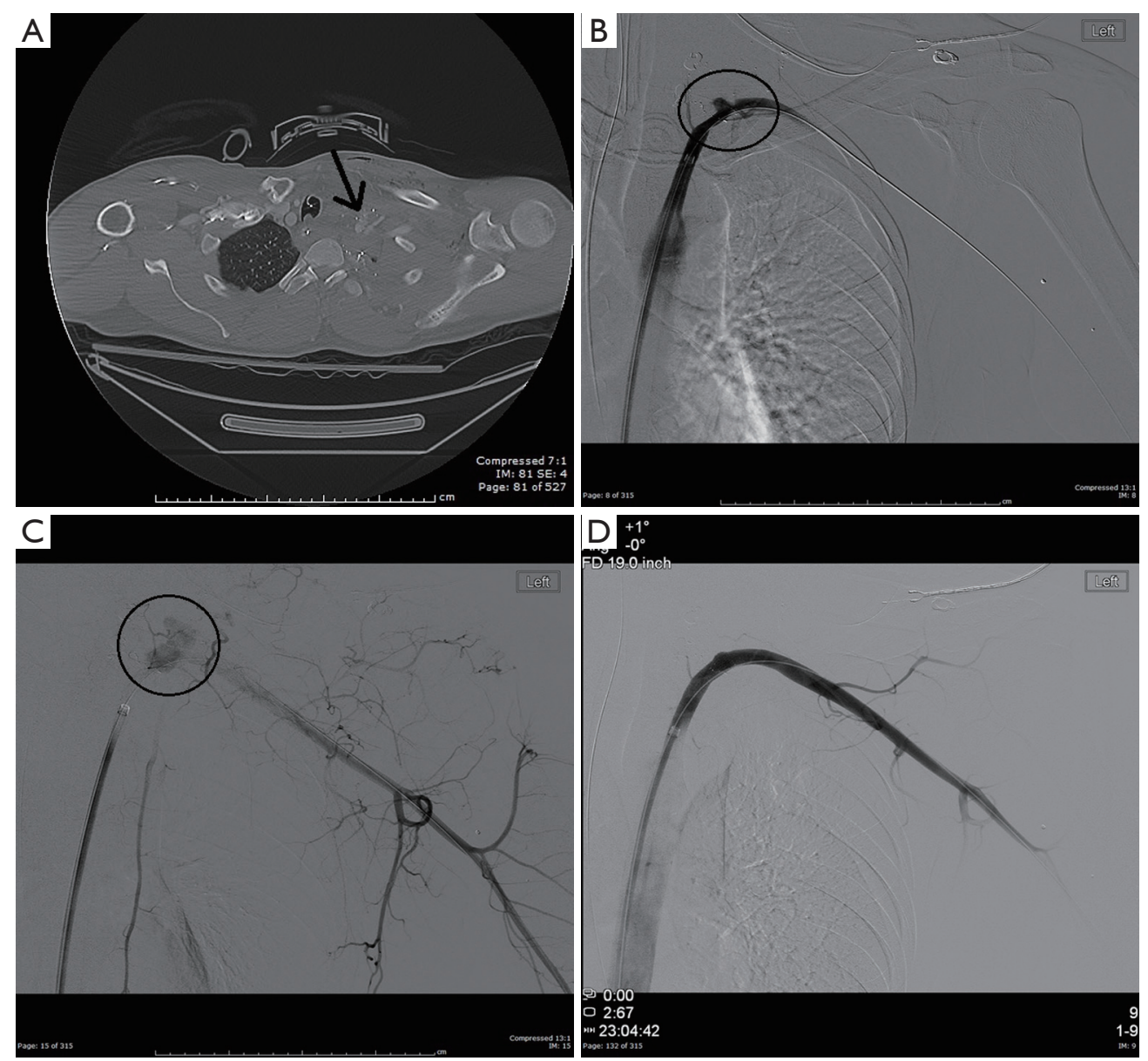

Figure 1 A 35-year-old male police officer shot multiple times by perpetrator. (A) Initial CTA shows multiple bullet fragments and left neck/chest hematoma with evidence of extravasation from the left subclavian artery (black arrow); (B) (early) and (C) (late) images from left subclavian angiogram showed irregularity and extravasation; (D) a covered stent (Gore ${ }^{\circledR}$ Viabahn ${ }^{\circledR}$ W.L. Gore Newark, DE, USA) was placed with resolution of irregularity and extravasation.

blood volume of $5 \mathrm{~L}$ ), vital signs often remain normal. While blood pressure may remain stable with loss of between $15-30 \%$ of circulating blood volume ( $750-1,500 \mathrm{cc}$ ), pulse rate increases to about 100-120 beats per minute (bpm). With blood loss of greater than $30 \%$ of circulating blood volume $(>1,500)$, hypotension will now be evident. Worsening tachycardia $(>120 \mathrm{bpm})$, significant tachypnea (respiratory rate $>30$ ), diminished urine output and significantly altered mental status (confusion or lethargy) are also frequently seen (16). With severe hemorrhagic shock, bradycardia can paradoxically be seen (17). While most causes of hypotension in trauma patients are secondary to hemorrhage (18), other causes to consider include neurogenic shock (19), pericardial tamponade (20) and tension pneumothorax (21). D focuses on neurologic disability, which is most commonly assessed and graded using the Glasgow Coma Scale.

\section{Timing of endovascular interventions}

Trauma embolization needs to occur expeditiously. The recent position statement from the Society of Interventional Radiology states that endovascular procedures for trauma should be available 24 hours a day and performed within 60 minutes of the decision to perform angiography (22). Rapid response time for hemorrhage control is imperative; the so called "golden hour", which is likely erroneously attributed to the famed founder the Shock Trauma Institute, Dr. Lerner (23), none-the-less 

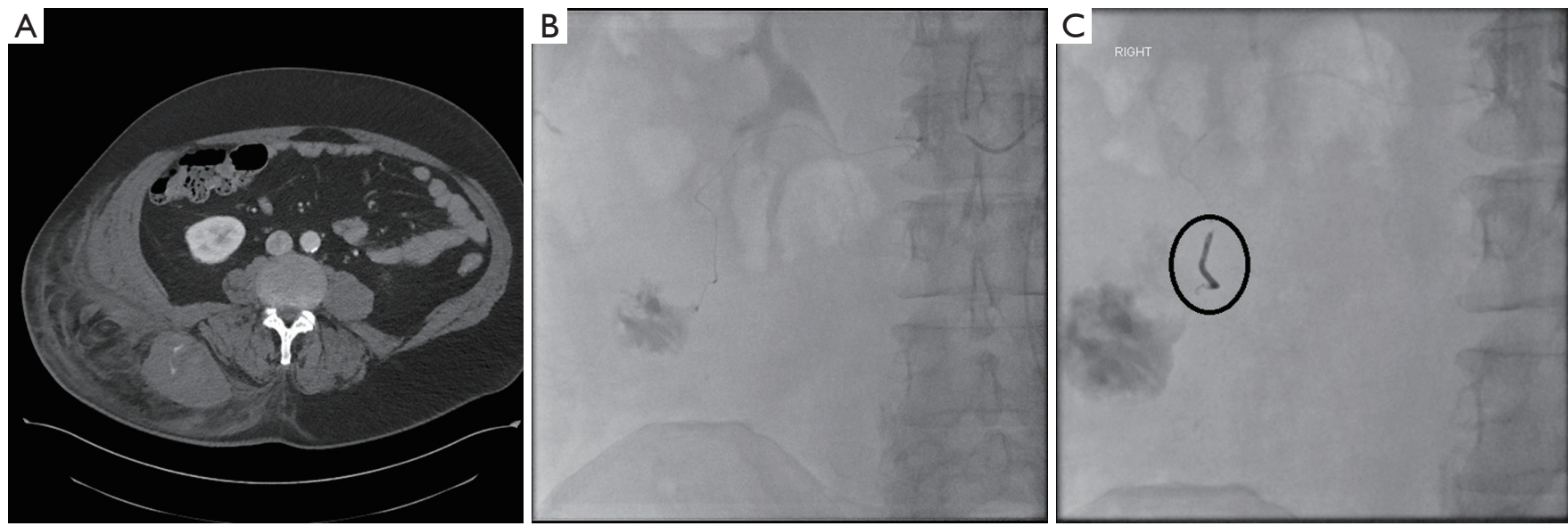

Figure 2 A 60-year-old male on Clopidogrel for coronary artery disease who fell 8 feet and has expanding right back hematoma. (A) Initial CT showing hematoma with active extravasation. (B) L2 lumbar artery selection with a reversed curve (Simmons-1) catheter and subselection with a microcathter to the branch feeding the extravasation. (C) A combination of coils (black circle) and gelfoam were used to embolize this branch. Patient's hematocrit stabilized and Clopidogrel was able to be restarted.

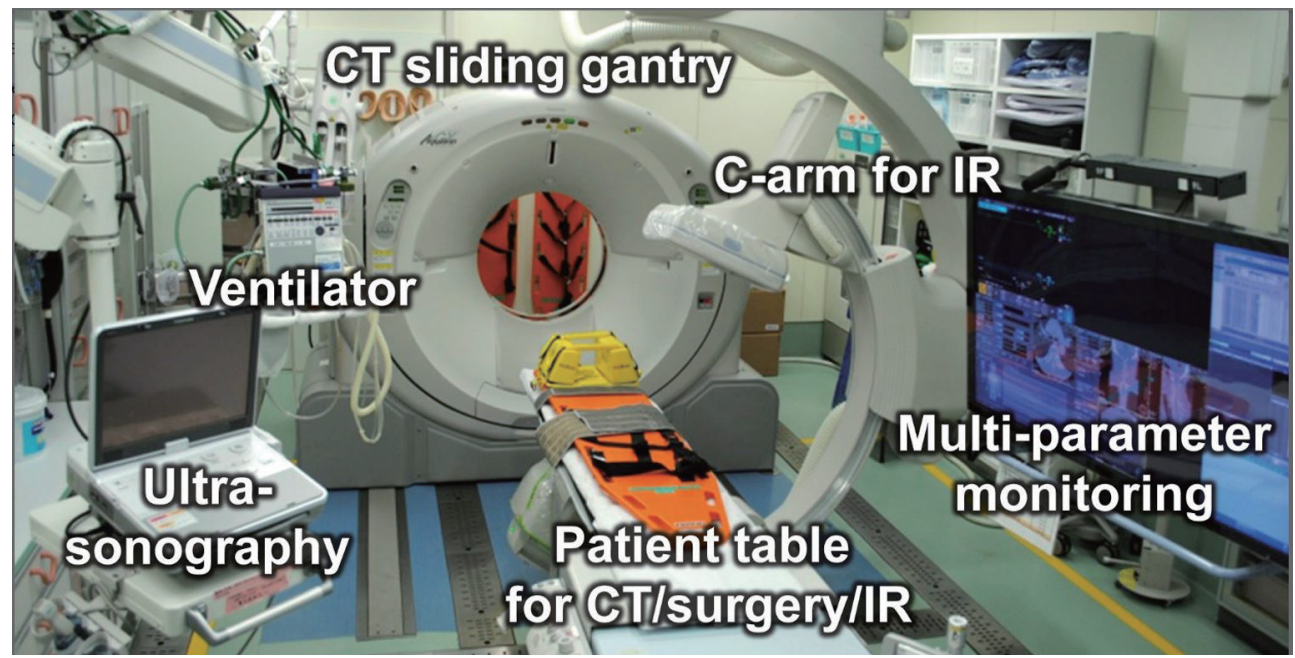

Figure 3 Multifunctional trauma room. The same table can be used for initial assessment, CT scanning, endovascular procedures and emergency surgeries [from (25); written permission obtained from corresponding author, Dr. Kazuma Yamakawa, MD, PhD].

underscores the importance of early and definitive care especially in cases of ongoing blood loss. The pinnacle of this shifting paradigm to reliance on endovascular procedures and expeditious embolization is creation of combination triage, computed tomography, operating and endovascular rooms without need for patient transfer or different tables $(24,25)$ (Figures 3,4$)$.

\section{Resuscitation in the angiography suite}

Permissive hypotension, is a controversial but promising strategy in which aggressive fluid resuscitation and aggressive blood transfusion is avoided and replaced with interventions only to reach a target MAP of $65 \mathrm{mmHg}$. This has been found to have higher rates of overall survival in the trauma setting and less blood loss (26). Normal saline boluses can lead to hemodilution, fluid overload and clot disruption. In the setting of concurrent brain injury, permissive hypotension is avoided 

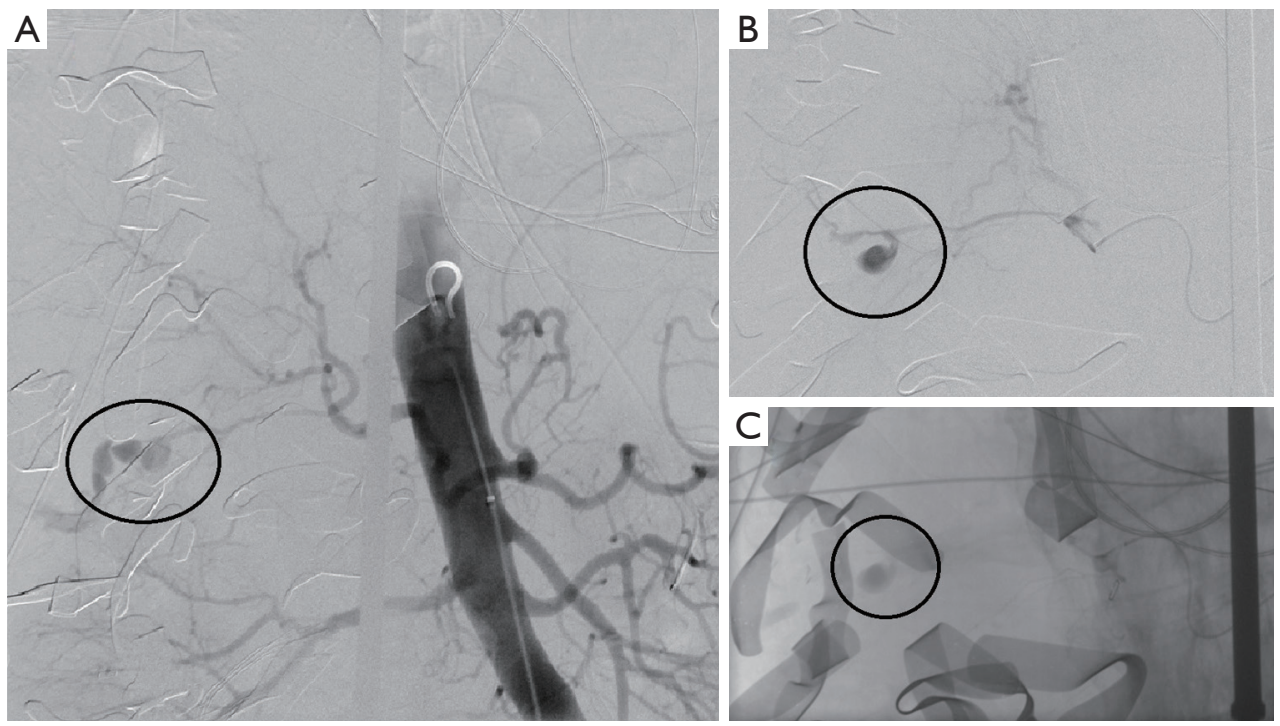

Figure 4 A 60-year-old man who was involved in a roll-over ATV accident who underwent ex-lap for large volume perihepatic hemoperitoneum and hypotension. Despite peri-hepatic packing, patient remained unstable. Given ongoing bleeding and shock, massive transfusion protocol was activated and embolization was performed in a hybrid operating room without need for transfer of patient. Initial aortogram (A) showed extravasation from the right hepatic artery. Selective angiograms show the pseudoaneurysm (B,C). The area of abnormality was subsequently successfully embolized with gelfoam slurry and coils.

as increased MAP is needed to maintain adequate cerebral perfusion pressure. When needed, transfusions should be should be administered at a 1:1:1 ratio of red blood cells, fresh frozen plasma and platelets in order to match whole blood components. Hypothermia should be avoided as it exacerbates underlying trauma induced coagulopathy (27).

\section{Conclusions}

Trauma is a leading cause of death and disability and predominately effects young patients. Trauma teams include many health care professionals from many subspecialties. Endovascular specialists such as interventional radiologists and vascular surgeons play an ever growing role in this team and in the care of these patients. In this focused series on endovascular interventions in trauma, articles will discuss the endovascular treatment of traumatic aortic injury, splenic, hepatic, renal pelvic and extremity trauma. Additionally, we include an article on the emerging technology of resuscitative endovascular balloon occlusion of the aorta (REBOA).

\section{Acknowledgments}

Funding: None.

\section{Footnote}

Provenance Peer Review: This article was commissioned by the editorial office, Annals of Translational Medicine for the series "Endovascular interventions in trauma". The article did not undergo external peer review.

Conflicts of Interest: The author has completed the ICMJE uniform disclosure form (available at http://dx.doi.org/10.21037/ atm-20-4418). The series "Endovascular interventions in trauma" was commissioned by the editorial office without any funding or sponsorship. KBQ served as the unpaid Guest Editor of the series and serves as an unpaid editorial board member 
of Annals of Translational Medicine from Aug 2019 to Jul 2021. The author has no other conflicts of interest to declare.

Ethical Statement: The author is accountable for all aspects of the work in ensuring that questions related to the accuracy or integrity of any part of the work are appropriately investigated and resolved.

Open Access Statement: This is an Open Access article distributed in accordance with the Creative Commons AttributionNonCommercial-NoDerivs 4.0 International License (CC BY-NC-ND 4.0), which permits the non-commercial replication and distribution of the article with the strict proviso that no changes or edits are made and the original work is properly cited (including links to both the formal publication through the relevant DOI and the license). See: https://creativecommons.org/licenses/by-nc$\mathrm{nd} / 4.0 \%$.

\section{References}

1. Centers for Disease Control and Prevention. Leading Causes of Death. 2017, March 17. Available online: https://www.cdc.gov/ nchs/fastats/leading-causes-of-death.htm

2. Quinn AC, Sinert R. What is the utility of the Focused Assessment with Sonography in Trauma (FAST) exam in penetrating torso trauma? Injury 2011;42:482-7.

3. Bookstein JJ, Goldstein HM. Successful management of postbiopsy arteriovenous fistula with selective arterial embolization. Radiology 1973;109:535-6.

4. Roy P, Mukherjee R, Parik M. Splenic trauma in the twenty-first century: changing trends in management. Ann R Coll Surg Engl 2018;100:1-7.

5. May AM, Darwish O, Dang B, et al. Successful Nonoperative Management of High-Grade Blunt Renal Injuries. Adv Urol 2016;2016:3568076.

6. Stassen NA, Bhullar I, Cheng JD, et al. Nonoperative management of blunt hepatic injury: an Eastern Association for the Surgery of Trauma practice management guideline. J Trauma Acute Care Surg 2012;73:S288-93.

7. Ultee KH, Soden PA, Chien V, et al. National trends in utilization and outcome of thoracic endovascular aortic repair for traumatic thoracic aortic injuries. J Vasc Surg 2016;63:1232-9.e1.

8. Wijffels DJ, Verbeek DO, Ponsen KJ, et al. Imaging and Endovascular Treatment of Bleeding Pelvic Fractures: Review Article. Cardiovasc Intervent Radiol 2019;42:10-8.

9. Quencer KB, Smith TA. Review of proximal splenic artery embolization in blunt abdominal trauma. CVIR Endovasc 2019;2:11.

10. Xu H, Min X, Li Y, et al. A Comparative Study of Conservation, Endovascular Embolization Therapy, and Surgery for Blunt Renal Trauma. Med Sci Monit 2020;26:e922802.

11. Smith RS, Chang FC. Traumatic rupture of the aorta: still a lethal injury. Am J Surg 1986;152:660-3.

12. Mouawad NJ, Paulisin J, Hofmeister S, et al. Blunt thoracic aortic injury - concepts and management. J Cardiothorac Surg 2020;15:62.

13. von Oppell UO, Dunne TT, De Groot MK, et al. Traumatic aortic rupture: twenty-year metaanalysis of mortality and risk of paraplegia. Ann Thorac Surg 1994;58:585-93.

14. Azizzadeh A, Ray HM, Dubose JJ, et al. Outcomes of endovascular repair for patients with blunt traumatic aortic injury. J Trauma Acute Care Surg 2014;76:510-6.

15. Eastridge BJ, Holcomb JB, Shackelford S. Outcomes of traumatic hemorrhagic shock and the epidemiology of preventable death from injury. Transfusion 2019;59:1423-8.

16. Kortbeek JB, Al Turki SA, Ali J, et al. Advanced trauma life support, 8th edition, the evidence for change. J Trauma 2008;64:1638-50.

17. Bell K, Elmograbi A, Smith A, et al. Paradoxical bradycardia and hemorrhagic shock. Proc (Bayl Univ Med Cent) 2019;32:240-1.

18. Carrick MM, Leonard J, Slone DS, et al. Hypotensive Resuscitation among Trauma Patients. Biomed Res Int 2016;2016:8901938.

19. Mallek JT, Inaba K, Branco BC, et al. The incidence of neurogenic shock after spinal cord injury in patients admitted to a highvolume level I trauma center. Am Surg 2012;78:623-6. 
20. Fitzgerald M, Spencer J, Johnson F, et al. Definitive management of acute cardiac tamponade secondary to blunt trauma. Emerg Med Australas 2005;17:494-9.

21. McPherson JJ, Feigin DS, Bellamy RF. Prevalence of tension pneumothorax in fatally wounded combat casualties. J Trauma 2006;60:573-8.

22. Padia SA, Ingraham CR, Moriarty JM, et al. Society of Interventional Radiology Position Statement on Endovascular Intervention for Trauma. J Vasc Interv Radiol 2020;31:363-9.e2.

23. Lerner EB, Moscati RM. The golden hour: scientific fact or medical "urban legend"? Acad Emerg Med 2001;8:758-60.

24. Ball CG, Kirkpatrick AW, D'Amours SK. The RAPTOR: Resuscitation with angiography, percutaneous techniques and operative repair. Transforming the discipline of trauma surgery. Can J Surg 2011;54:E3-4.

25. founding members of the Japanese Association for Hybrid Emergency Room S. The hybrid emergency room system: a novel trauma evaluation and care system created in Japan. Acute Med Surg 2019;6:247-51.

26. Tran A, Yates J, Lau A, et al. Permissive hypotension versus conventional resuscitation strategies in adult trauma patients with hemorrhagic shock: A systematic review and meta-analysis of randomized controlled trials. J Trauma Acute Care Surg 2018;84:802-8.

27. Kornblith LZ, Moore HB, Cohen MJ. Trauma-induced coagulopathy: The past, present, and future. J Thromb Haemost 2019;17:852-62.

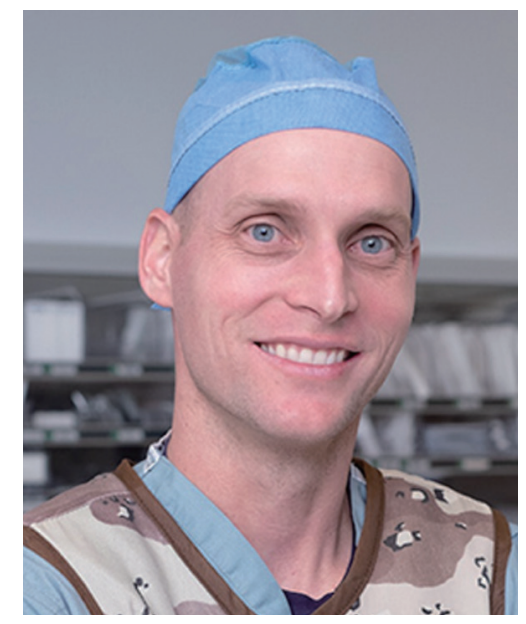

Keith Bertram Quencer

Keith Bertram Quencer Division of Interventional Radiology, Department of Radiology, University of Utah, Salt Lake City, UT, USA.

(Email: kbquencer@gmail.com)

Submitted Jun 01, 2020. Accepted for publication Aug 13, 2020.

doi: $10.21037 / \mathrm{atm}-20-4418$

View this article at: http://dx.doi.org/10.21037/atm-20-4418

Cite this article as: Quencer KB. Endovascular interventions in trauma, an introduction. Ann Transl Med 2021;9(14):1191. doi: 10.21037/atm-20-4418 